\title{
Numerical and Experimental Studies on Fixture-Workpiece Contact and Structural Deformations in Pocket Milling
}

\author{
M. Yadav ${ }^{1 *}$, S. Mohite ${ }^{2}$ \\ ${ }^{1}$ Research Scholar, Government College of Engineering, Karad,India \\ ${ }^{2}$ Professor, Government College of Engineering, Karad, India \\ \{mhyadav_gcek@rediffmail.com\}
}

\begin{abstract}
Geometrical inaccuracies, in a statically clampedworkpiece subjected to cutting forces,aremainly caused by the contact deformationsat the locators and the structural deformations in the body of the workpiece.In addition, during machining the structural deformations continuously increase as the workpiece keeps losing its stiffness on account of metal removal. This condition is also encountered while machining thin walled workpieces. To investigate the relative significance of the structural and the contact deformations,fixture elements workpieceand the contact at their interface is modelled numerically in ANSYS 17.2.A milling fixture with 3-2-1 location principle and two hydraulically operated clamps is developed for pocket milling operation on Al-6061-T6 and a number of experiments are conducted to obtain structural deformation of workpiece. The numerical simulations and experiments were performed for different percentages of metal removal $(0 \%, 20 \%$ and $50 \%$ ) under various clamping pressures varying from $15-25 \mathrm{bar}\left(\mathrm{kg} / \mathrm{cm}^{2}\right)$. The numerically predicted deformations show a good agreement with experimental results. The studies would help in developing an adaptive clamping mechanism to compensate for the changing structural stiffness of the workpiece and thereby keeping a check on the deformations, and hence the machining accuracies.
\end{abstract}

Keywords: Hertzian contact, workpiece compliance, fixture-workpiece, adaptive clamping, metal removal effect

\section{Introduction}

After successful integration of fixture design and analysis with CAD/CAM, Computer Aided Fixture Design Systems (CAFD) is progressing towards integration of hardware elements (mainly sensors and actuators) in the fixture combined with the necessary control algorithms to realize intelligent fixtures [1,2].The common functions of fixtures are improved from only securely holding and accurately locating the workpiece considered as a rigid body, to integrate additional functions taking into account aspects like the deformations, vibrations and distortions in the workpiece during processing as a consequence of the variations in the dynamic behaviour of the fixture workpiece system.

A good fixture design provides positional accuracy, workpiece stability and an acceptable workpiece deformation and displacement, during machining. In order to meet high production demands, the high metal removal rates and high clamping forces become inevitable. Clamping forces play an important role in determining the workpiece stability and accuracy. The clamping force applied must be large enough to restrain the workpiece motion completely during machining. Localized contact forces are developed due to clamping forces at contact interfaces. Excessive contact forces cause elastic or plastic deformations of workpiece at contact regions and insufficient contact forces cause slip or lift-off at the workpiece and locators/ clamps interface[3]. Therefore, it is necessary to study the effect of the clamping force on the overall workpiece deformations [4]. Siebenaler et al., investigated the effects of various finite element modelling parameters, such as friction and meshdensity, on workpiece deformation. In addition to modelling the workpiece and fixture tips, as is common, the effect of compliance of other fixture components such as support blocks, base plate, etc., on workpiece deformation is also examined in this work. The FEA predictions of workpiece deformationand locator reactions are experimentally verified [5].The layout of fixture including clamp and locator layout play an important role in fixture performance. Vishnuprian et al. suggested fixture layout optimization by taking into consideration the effect locator errors. The study presented deterministic location ensured throughout the optimization process and minimal machining errors [6].

B. Iyer, S. Nalbalwar and R. Pawade (Eds.)

ICCASP/ICMMD-2016. Advances in Intelligent Systems Research.

Vol. 137, Pp. 212-219.

(C) 2017. The authors - Published by Atlantis Press

This is an open access article under the CC BY-NC license (http://creativecommons.org/licens)es/by-nc/4.0/).

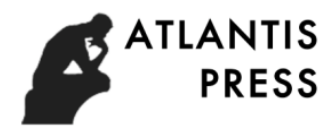


During machining, workpiece experiences motion due to cutting and clamping forces. This affects the location accuracy and final part quality to a considerable extent.Jamdar et al. presented tracking of workpiece stability under spatially varying cutter position and continuouslydecreasing mass and compliance of a workpiece during pocket milling operation [7]. Adaptive clamping or varying cutting parameters is the remedial measure to control the workpiece deformations. With this objective, in this paper,the workpiece deformations are tracked under varying clamping pressures and different percentages of metal removal during pocket milling operation. In the following sections, analytical model based on Hertzian contact theory is presented to estimate contact deformations, this is followed by numerical predictions and experimental measurements.

\section{Analytical model}

The analytical model is based on the Hertzian contact theory. The workpiece remains in static equilibrium under the action of clamps and its own weight. The elastic deformation of the workpiece occurs at a fixture-workpiece contact due to clamping forces and reactions at the locators. Therefore the contact reaction force must be known. For this, the principle of minimum total complementary energy is applied to develop a model that gives the reaction force at each fixture-workpiece contact. The complementary energy of fixture-workpiece contacts can be computed from the contact force-displacement relationships, as given in the contact mechanics literature. A prismatic workpiece of Al 6061-T-6 $(100 \mathrm{~mm} \times 100 \mathrm{~mm} \times 70 \mathrm{~mm})$ is located in 3-2-1 fixture as shown in figure 1.

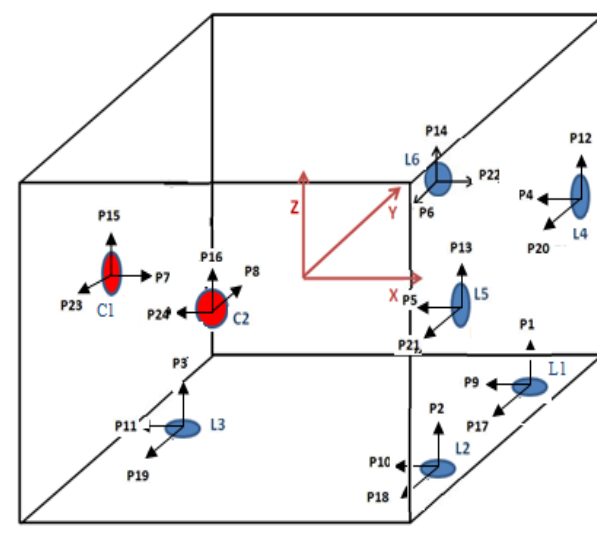

(a)

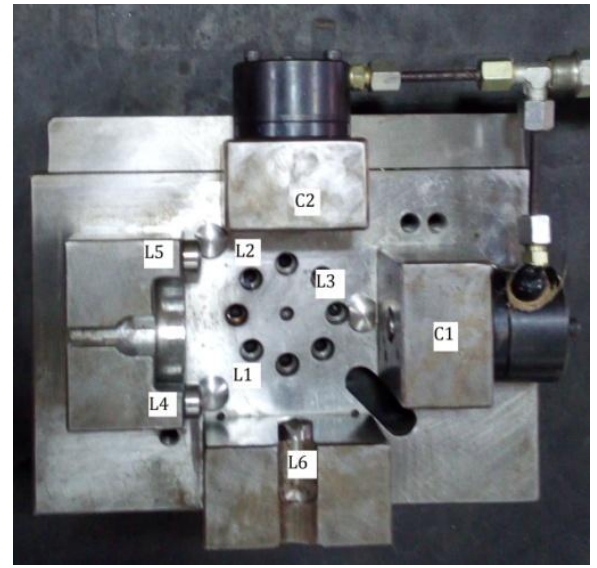

(b)

Fig. 1. (a)Fixture-workpiece system with local contact forces (b) Experimental set up of fixture layout with six locators and two clamps

The material properties of Al 6061-T6 workpiece and fixture elements are given in the following Table 1.

Table 1 Properties of workpiece and fixture element

\begin{tabular}{|c|l|c|c|}
\hline Sr. No. & \multicolumn{1}{|c|}{ Parameter } & Workpiece & Spherical Locator \\
\hline 1 & Material & Al-6061-T6 & Hardened steel \\
\hline 2 & Dimensions $(\mathrm{mm})$ & $100 \times 100 \times 70$ & Spherical tipped $(r=19.81 \mathrm{~mm})$ \\
\hline 3 & Young's modulus E $(\mathrm{GPa})$ & 70 & 200 \\
\hline 4 & Poisson's ratio & 0.33 & 0.285 \\
\hline 5 & Yield strength $(\mathrm{Sy})(\mathrm{MPa})$ & 270 & $(300-400)$ \\
\hline 6 & Shear modulus $(\mathrm{GPa})$ & 26.31 & 77.82 \\
\hline 7 & Density $\left(\mathrm{kg} / \mathrm{m}^{3}\right)$ & 2700 & 6 locator, 2 clamps \\
\hline 8 & Weight $(\mathrm{kg})$ & 1.89 & - \\
\hline 9 & Static coefficient of friction & 0.375 & \\
\hline
\end{tabular}

Table 2 below lists the coordinates of the fixture elements, viz., locators and clamps. 
Table 2 Layout of fixture element

\begin{tabular}{|c|c|c|c|}
\hline $\begin{array}{c}\text { Fixture } \\
\text { Element }\end{array}$ & $\mathrm{X}_{\mathrm{g}}(\mathrm{mm})$ & $\mathrm{Y}_{\mathrm{g}}(\mathrm{mm})$ & $\mathrm{Z}_{\mathrm{g}}(\mathrm{mm})$ \\
\hline $\mathrm{L}_{1}$ & 45 & 45 & -35 \\
\hline $\mathrm{L}_{2}$ & 45 & -45 & -35 \\
\hline $\mathrm{L}_{3}$ & -45 & 1 & -35 \\
\hline $\mathrm{L}_{4}$ & 50 & 40 & 1 \\
\hline $\mathrm{L}_{5}$ & 50 & -40 & 1 \\
\hline $\mathrm{L}_{6}$ & 1 & 50 & 1 \\
\hline $\mathrm{C}_{1}$ & -50 & 1 & 1 \\
\hline $\mathrm{C}_{2}$ & 1 & -50 & 1 \\
\hline
\end{tabular}

Abrief outline of the Hertzian contact theory is given below. First, the contact radius is obtained as follows.

$$
\mathrm{a}=\left(\frac{3 \mathrm{P}_{\mathrm{i}}}{4 \mathrm{E}^{*}}\right)^{\frac{1}{3}}
$$

$\mathrm{R}$ - Relative curvature at contact $\left(\frac{1}{\mathrm{R}}=\frac{1}{\mathrm{R}_{\mathrm{w}}}+\frac{1}{\mathrm{R}_{\mathrm{f}}}\right)$ with $\mathrm{R}_{\mathrm{w}}$ is the local radius of the workpiece and $\mathrm{R}_{\mathrm{f}}$ is the radius of the spherical tip.

$$
E^{*}=\left[\left(\frac{1-v_{w}^{2}}{E_{w}}\right)+\left(\frac{1-v_{f}^{2}}{E_{f}}\right)\right]^{-1}
$$

The total complementary energy for all $(\mathrm{L}+\mathrm{C})$ contact is written as

$\Pi_{\mathrm{c}}=\sum_{\mathrm{i}=0}^{\mathrm{L}+\mathrm{C}} \int_{0}^{\mathrm{P}_{\mathrm{i}}} \delta_{\mathrm{izc}} \mathrm{dP} \mathrm{P}_{\mathrm{i}}+\int_{0}^{\mathrm{Q}_{\mathrm{ix}}} \delta_{\mathrm{ixc}} \mathrm{dQ} \mathrm{Q}_{\mathrm{ix}}+\int_{0}^{\mathrm{Q}_{\mathrm{iy}}} \delta_{\mathrm{iyc}} \mathrm{dQ} \mathrm{Q}_{\mathrm{iy}}$

To find the reaction forces complementary energy equation for the assemblage of clamps, locators and workpiece is minimized under the constraints. Thus, the objective function is minimization of the total complementary energy at contact.

$$
\min \Pi_{c}\left(P_{i}, Q_{\text {ix }}, Q_{\text {iy }}\right)
$$

Subjected to: Linear constraint and nonlinear constraint

$$
\begin{aligned}
\sum \mathrm{F}=0 \text { and } \sum \mathrm{M}= & 0 \\
\left(\sqrt{\left(\mathrm{Q}_{\mathrm{ix}}^{2}+\mathrm{Q}_{\mathrm{iy}}{ }^{2}\right)}\right) \leq \mu * \mathrm{P}_{\mathrm{i}} & \\
& \mathrm{P}_{\mathrm{i}} \geq 0(\mathrm{i}=1,2 \ldots \ldots \mathrm{L}+\mathrm{C}) \\
& \mathrm{P}_{\mathrm{i}} \leq \mathrm{S}_{\mathrm{y}} \mathrm{A}_{\mathrm{i}} \\
& \mathrm{P}_{\mathrm{j}}=\mathrm{F}_{\mathrm{cj}}(\mathrm{j}=1,2 \ldots \mathrm{C}+1)
\end{aligned}
$$

Solving equation (4) and (5) yields the contact reaction forces, $P_{i z}, Q_{i x}$ and $Q_{i y}$ with $i=1$ to $(L+C)$.

For a spherical-tipped fixture element pressed against a curved workpiece surface, the relationship for deformations is given by eq. (6) and (7) below,

$\delta_{\mathrm{iz}}=\left(\frac{9 \mathrm{P}_{\mathrm{i}}{ }^{2}}{16 \mathrm{RE}^{* 2}}\right)^{\frac{1}{3}}$ 
$\delta_{j}=\frac{Q_{j}}{8 a}\left(\frac{2-v_{w}}{G_{w}}+\frac{2-v_{f}}{G_{f}}\right)$ for $j=x$ or $y$

where, $\mathrm{P}_{\mathrm{iz}}$ and $\delta_{\mathrm{iz}}$ represent normal force and normal deformation. $\mathrm{Q}_{\mathrm{j}}$ and $\delta_{\mathrm{j}}$ represent tangential force and tangential deformation.

It should be noted here that the net deformation of the workpiece consists of two components, viz., the local contact deformation as discussed above and the structural deformation caused by workpiece compliance. The local contact deformation is obtained quite accurately using the Hertzian contact theory discussed above; however, there are no closed form formulae for finding out structural deformations of the workpiece. Hence, we use numerical modelling in ANSYS is done, to obtain the contact and structural deformation as described in the following section.

\section{Numerical model}

Prismatic Aluminium work piece resting on 3 spherical locators in horizontal base plane, butting against 2 and 1 spherical locators, respectively, in two mutually perpendicular vertical planes is modelled in ANSYS Workbench 17.2. These six locators (3-2-1) are constrained (ux, uy uz $=0$ ). Clamping forces are then applied at the back of two more spherical clamps in the remaining two vertical planes as shown in Figure2. The model is meshed using CONTA 174 (for work piece) and TATGET 170(for six locators and two clamps). Frictional contact is established between contact and target surfaces witha pin-ball region of $3 \mathrm{~mm}$ radius. Augmented Lagrange formulation is used for solution with ramping effect of clamping forces, (see, figure 2 (a) and (b)).

Simulations are performed to investigate the workpiece deformations (contact and structural) for $0 \%, 20 \%$ and $50 \%$ metal removal at clamping pressures ranging from $15-25 \mathrm{~kg} / \mathrm{cm} 2$. Images of the post processed results are shown in figure 2 (c), (d), (e) and (f). The contact (dimple) and structural deformations are clearly visible in figure 2 (c). Detailed results obtained under different conditions are presented in result and discussion section.

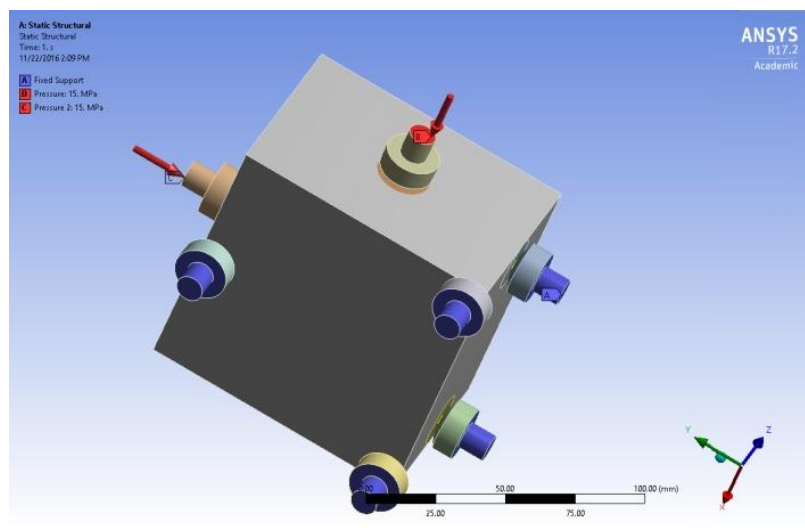

(a)

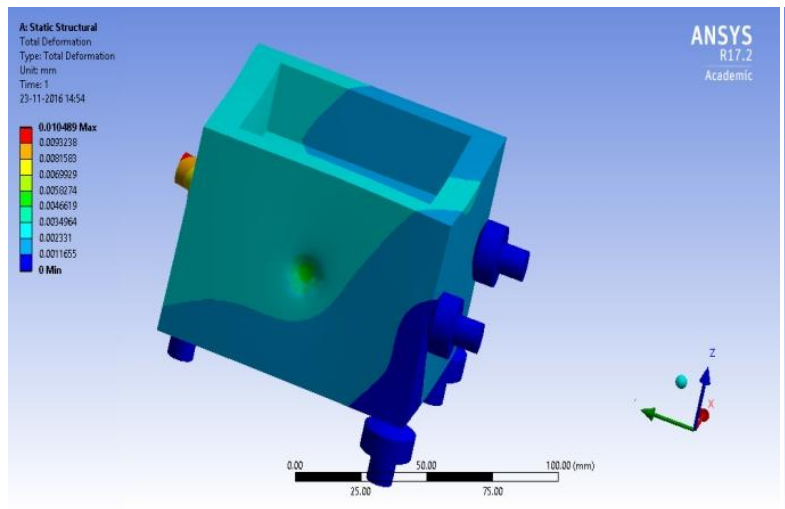

(c)

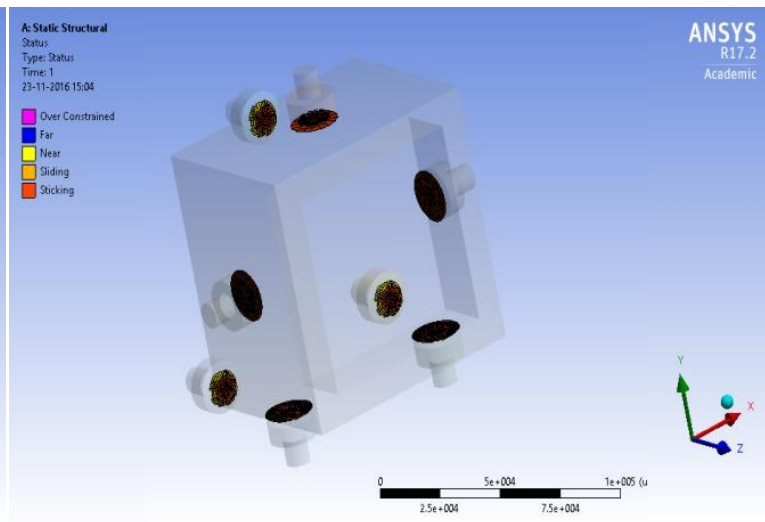

(b)

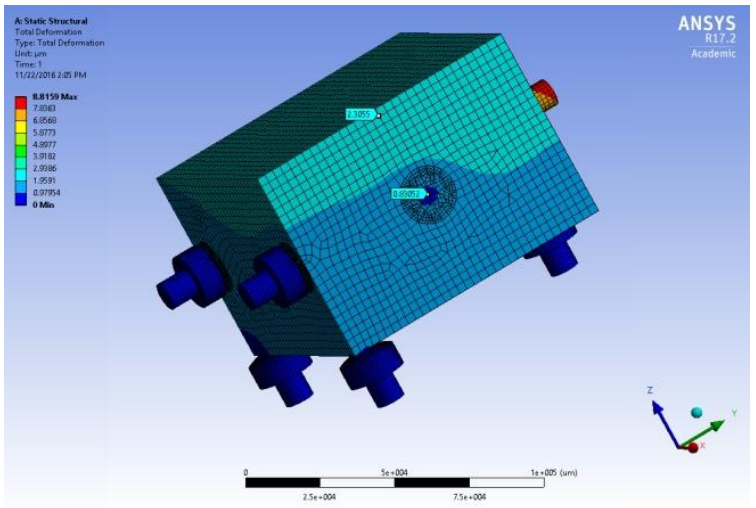

(d) 


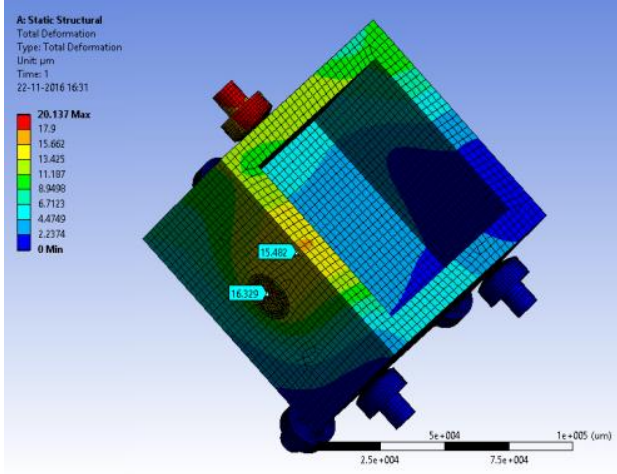

(e)
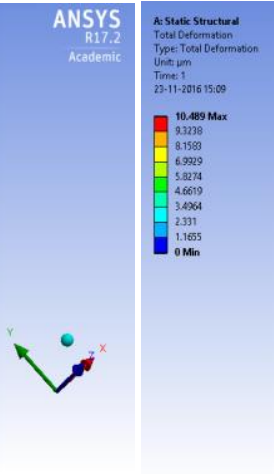

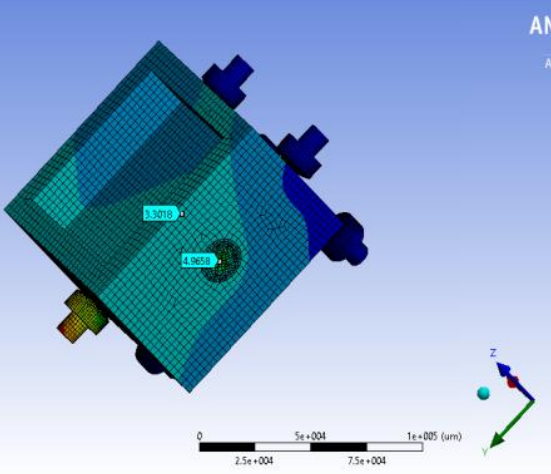

(f)

Fig. 2. (a) Solid model showing fixed supports at six locators and clamping pressures applied on two clamps, (b)Contact status showing sticking condition at all contacts,(c) Deformation at contact point, (d)Deformation of solid workpiece due to clamping forces at clamp C2, (e) Deformation of workpiece with 50\% metal removal, (f)

Deformation of workpiece with $20 \%$ metal removal due to clamping forces at clamp C2

To validate numerical results, elaborate experiments are performed on a specially designed fixture as described in the next section.

\section{Experimental Measurements}

Aluminium 6061-T6 workpiece,located and securely held with two hydraulically operated clampsin asufficiently rigid 3-2-1 fixture, is seen in photographs of figure 3 (a) and (b) below. A number of experiments are carried out on the fixture to measure the workpiece deformations using dial gauges of $1 \mu \mathrm{m}$ least count. The hydraulic actuators are operated by a hand pump equipped with a pressure gauge $(0-70 \mathrm{~kg} / \mathrm{cm} 2)$. With this arrangement, experimentally, it is possible to measure the net deformations (contact plus structural) are measured.

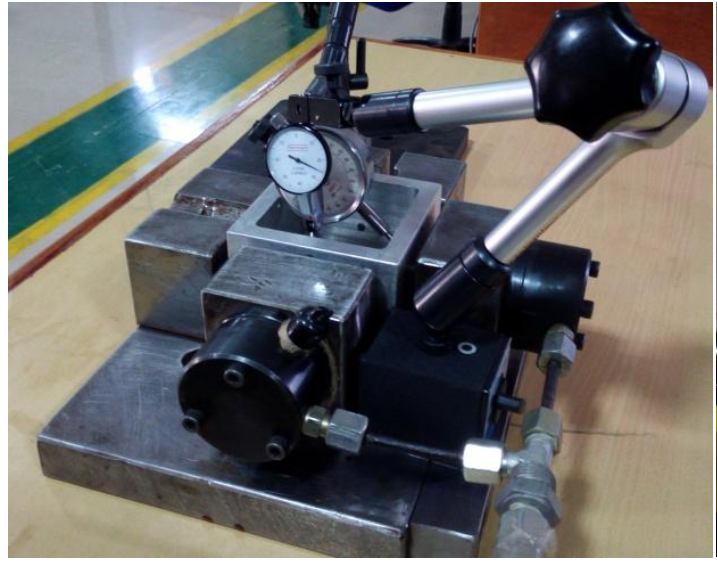

(a)

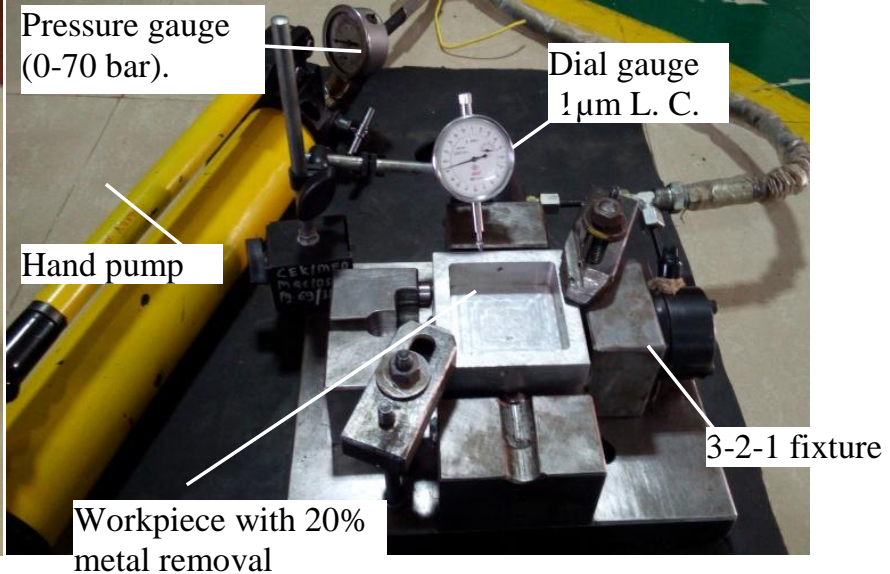

(b)

Fig. 3. Experimental set up with (a) two dials of $1 \mu \mathrm{m}$ least count measuring deformations at clamps (b) Top clamps to prevent lift-off of workpiece from the bottom plane

In the next section, a comparison of results obtained by numerical simulations and experimental work is presented. 


\section{Results and discussion}

In this section, section the results of static deformations of the clamped workpiece obtained by numerical simulation in ANSYS Workbench and experimental measurements are presented. The results are compared; errors are calculated and presented in Table 3, below. A maximum of $26.79 \%$ variation is observed particularly at higher clamping pressure.

Table 3 The comparison of analytical, numerical and experimental contact deformations of contact points and structural deformations of solid work piece at various clamping pressures

\begin{tabular}{|c|c|c|c|c|}
\hline $\begin{array}{c}\text { \% Metal } \\
\text { removal in } \\
\text { pocket }\end{array}$ & $\begin{array}{c}\text { Pressure } \\
(\text { bar })\end{array}$ & $\begin{array}{c}\text { Numerical deformation } \\
\left(\delta_{\mathrm{n}}\right) \mu \mathrm{m}\end{array}$ & $\begin{array}{c}\text { Experimental } \\
\text { deformation } \\
\left(\delta_{\mathrm{e}}\right) \mu \mathrm{m}\end{array}$ & $\begin{array}{c}\text { \% Error } \\
\left(\delta_{\mathrm{e}}-\delta_{\mathrm{n}}\right) / \delta_{\mathrm{e}} \mathrm{x} 100\end{array}$ \\
\hline \multirow{2}{*}{0} & 15 & 2.62 & 3.0 & 12.67 \\
\cline { 2 - 5 } & 20 & 5.92 & 14.0 & 26.00 \\
\cline { 2 - 5 } & 25 & 10.25 & 4.0 & 26.79 \\
\cline { 2 - 5 } & 20 & 3.61 & 9.0 & 26.33 \\
\cline { 2 - 5 } & 25 & 6.63 & 18.0 & -0.17 \\
\hline \multirow{2}{*}{50} & 15 & 14.03 & 6.0 & -11.09 \\
\cline { 2 - 5 } & 20 & 6.01 & 11.0 & 18.35 \\
\cline { 2 - 5 } & 25 & 9.78 & 20.0 & 22.06 \\
\hline
\end{tabular}

$\delta$ n- deformation obtained numerically, $\delta \mathrm{e}$ - deformation obtained experimentally, MR- percentage metal removal

In experimental measurements it is difficult to probe near the contact region, in spite of this, the overall match is quite satisfactory. The variation of workpiece deformation with $\%$ metal removal obtained numerically and experimentally, for different clamping pressures, is shown in Figure 4 (a) and (b), respectively. The agreement is quite well with a maximum deviation within $26 \%$. These lines of relatively constant slope, in a sense, are the dynamic characteristics of the workpiece under metal removal during machining. Thus, the numerical approach is validated and can very well be used to predict the workpiece deformations.
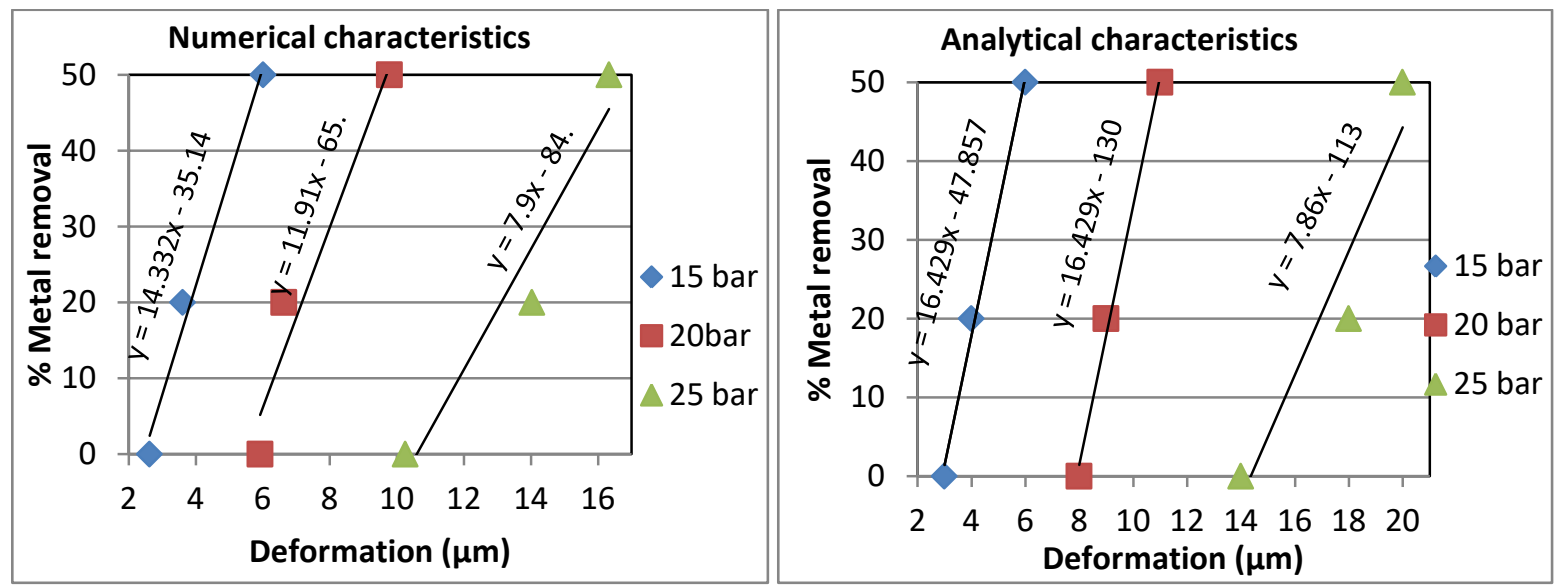

Fig. 4. Effect of \%metal removal on workpiece deformation (at/near C2) obtained (a) Numerically (b) Experimentally for different clamping pressures 
The aim of the current study is to counter the effect of metal removal on workpiece deformation by controlling the clamping pressure. This is demonstrated by the clamping pressure versus workpiece deformation characteristics depicted, for different \% metal removal, in Figure 5 (a) and (b), respectively. Thus, this characteristic will be used in the

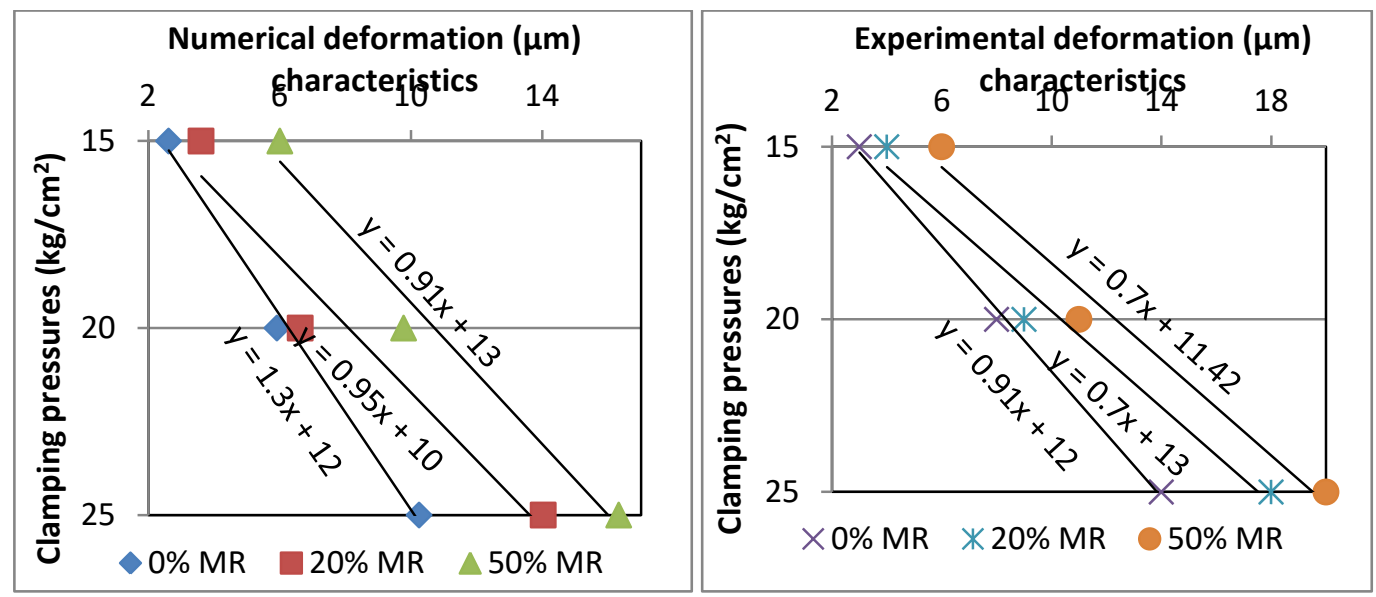

Fig. 5. Variation of workpiece deformations(at C2) with different clamping pressures (at/near C2) obtained (a) Numerically (b) Experimentallyfor effect of metal removal on workpiece deformation

control strategy of the adaptive clamping implementation. Lastly, the numerical and experimental trends are seen to match quite well implying that the workpiece behaviour can be predicted before hand and further it can be controlled by manipulating clamping pressure adaptively, which is the further scope of the work.

\section{Conclusions}

Machining thin walled work pieces or components involving substantial metal removal involves vibrations and deformations of the work piece affecting its quality. Accurate prediction of these deformations is essential to mitigate these deformations by manipulating cutting forces and/or clamping forces in-process. In this work, a numerical approach is presented to predict the workpiece deformations. The results are validated experimentally for different clamping pressures and percentages of metal removal. The numerical results are found to match within $26 \%$ with the experimental results. The developed framework will help in implementation of adaptive clamping to counter the work piece deformations due to metal removal and obtain machining according to required precision, quality and cost. Further, the numerical approach and can be integrated with Computer Aided Fixture Design (CAFD) tools adding to its intelligence.

\section{Acknowledgement}

The work is supported by the R and D grant under TEQIP-II project at the Government College of Engineering, Karad.

\section{References}

[1] S. K. Hargrove A. Kusiak, "Computer-aided fixture design: a review" International Journal of Production Research (2007) 733-753.

[2] Manisha Yadav and Suhas Mohite, "Development of a decision support system for fixture design", CCIS 145, (C) Springer-Verlag Berlin Heidelberg (2011) 182-189. 
[3] James N. Asante, "A combined contact elasticity and finite element-based modelfor contact load and pressure distribution calculationin a frictional workpiece-fixture system" International Journal Advanced Manufacturing Technology (2008) 39:578-588

[4] Haiyan Deng, "Analysis and synthesis of fixturing dynamic stability in machining accounting formaterial removal effect”, A Ph. D thesis submitted to the Georgia Institute of Technology Atlanta, Georgia, (2006)

[5] Shane P. Siebenaler, Shreyes N. Melkote, "Prediction of workpiece deformation in a fixture systemusing the finite element method" International Journal of Machine Tools and Manufacture 46 (2006) 51-58

[6] Vishnuprian et al., "Optimization of machining fixture layout for tolerance requirements under the influence of locating errors" International Journal of Engineering, Science and TechnologyVol. 2, No. 1, (2010) 152162

[7] Jamdar S.B. et al., "Tracking workpiece stability under varying cutter positions, mass and compliance of workpiece in pocket milling", International Journal of Research in Engineering and Technology, Vol. 5, Special Issue: 13, (2016) 132-138 